\title{
KINETICS OF COPPER AND CADMIUM CEMENTATION BY ZINC POWDER
}

\author{
Vitor de Andrade Alvarenga Oliveira ' \\ José Márcio Soares Penna ' \\ Lucas Sanches Magalhães ' \\ Versiane Albis Leão' \\ Cláudio Gouvea dos Santos ${ }^{2}$
}

\begin{abstract}
The cementation of copper and cadmium by zinc powder was investigated in order to assess the influence of different parameters in the process. The results showed that the process follows a first order reaction with two stages in both systems. In the system $\mathrm{Cu} / \mathrm{Zn}$, the second stage is faster than the first while in the system $\mathrm{Cd} / \mathrm{Zn}$ the second stage is slower than the first. In the system $\mathrm{Cu} / \mathrm{Zn}$, the variation on the surface area of copper cement followed a power law and a straight line was obtained by plotting $-\ln \left(\left[\mathrm{Cu}^{2+}\right] /\left[\mathrm{Cu}^{2+}\right]_{0}\right)$ against $\mathrm{t}^{3 / 2}$, the activation energy was calculated as $\left.16.3 \mathrm{k}\right]$. In the system $\mathrm{Zn} / \mathrm{Cd}$ the surface area available for reaction decreased as a result of the cement agglomeration. On the experiments carried out with ions $\mathrm{Cu}^{2+}$ and $\mathrm{Cd}^{2+}$ in solution, purer copper cement was obtained when the experiments were carried out in the presence of less than stoichiometric amount of zinc powder and longer reaction times.
\end{abstract}

Keywords: Cementation; Kinetics; Copper and cadmium.

\section{INTRODUCTION}

Cementation is an electrochemical process by which a metallic ion in solution is reduced on the surface of a less noble metal, that is to say, a more electronegative metal is reduced on the surface of a more electropositive metal. The corresponding electrochemical reaction can be represented by the following Equation I:

$$
y M^{X+}+x N^{0} \leftrightarrow x N^{y+}+y M^{0}
$$

Where $M^{x+}$ and $M^{0}$ are the ionic and metallic forms of the more electronegative metal and $N^{\gamma+}$ and $N^{0}$ are the ionic and metallic forms of the more electropositive metal [I-7].

Cementation reactions play an important role in the purification and recovering of metallic ions from industrial waste stream or process solutions $[8,9]$. The spontaneity of these reactions as well as the equilibrium concentrations of the metallic ions can be estimated by using thermodynamic data. In the cementation of copper ions by metallic zinc powder (Equation 2), for example, the resulting potential difference is I.I V.

$$
\mathrm{Zn}^{0}+\mathrm{Cu}^{2+} \leftrightarrow \mathrm{Zn}^{2+}+\mathrm{Cu}^{0}
$$

Nernst equation can be used to calculate the equilibrium constant for the reaction (Equation 3 ), which in this case gives:

$$
K_{e q}=\exp \left(\frac{n F}{R T} \Delta E^{0}\right)=1.94 \times 10^{37}
$$

The result indicates a spontaneous reaction for which the equilibrium concentration of $\mathrm{Zn}^{2+}$ will be much higher than $\mathrm{Cu}^{2+}$, if one considers solid species activities equal to one and an ideal solution behaviour [I]. Thus, the thermodynamic results suggest that the final concentration of copper ions will be very low when metallic zinc is used to remove those ions from aqueous solutions. This great efficiency in removing metals from solution through cementation supports the use of such procedure in the so called Roasting-Leaching-Electrolysis (RLE) process to produce zinc. In this process, a liquor originated in the leaching step must be purified by removal of metals originally present in the ore and solubilized by the leaching solution.

In the RLE process, the most common foreign metals present in the leaching liquor are $\mathrm{Cd}^{2+}, \mathrm{Ni}^{2+}, \mathrm{Co}^{2+}$ and $\mathrm{Cu}^{2+}[\mathrm{IO}]$. The concentration of these ions is related to the content of the corresponding metals in the zinc ore concentrate prior to the roasting step. Since these metals must be removed from the "pregnant" leaching solution (PLS) to prevent the zinc cathodes from being contaminated in the electrolysis step, it is possible to turn the noble-metal-rich cement into a special by-product in RLE plants [ $1 \mathrm{I}-\mathrm{I} 3$ ] If noble metals in the roasted ore concentrate are present in suitable levels the implementation of a route to extract them from the cement may become economically viable.

Given the market value of the various metals present in the leaching liquor, it would be advantageous

'Departamento de Engenharia Metalúrgica e de Materiais, Universidade Federal de Ouro Preto - UFOP, Campus Morro do Cruzeiro, Ouro Preto, MG,

Brasil.E-mail: victor@ufop.edu.br

${ }^{2}$ Departamento de Química, Universidade Federal de Ouro Preto - UFOP, Campus Morro do Cruzeiro, Ouro Preto, MG, Brasil. 
to selectively remove these metals from solution, so that the resulting purer cement could be used as raw material for some other specific product. One such example is the cementation of copper, from which the cement could be subsequently leached by treatment with $\mathrm{H}_{2} \mathrm{SO}_{4}$, in order to produce copper sulfate. A possible drawback from this process, however, would be the contamination of the cement by cadmium resulting in the contamination of the copper sulfate as well. Considering that copper sulfate is usually added to forage as micronutrient, the presence of cadmium would certainly have undesirable consequences.

Although cadmium is considerably more soluble than copper, leaching of the contaminated cement may result in considerable loss of copper without completely removing cadmium. Moreover, operation costs can soar by handling the material and the need of several tanks for the purification steps.

This work presents some exploratory studies aiming at evaluating the influence of such parameters as temperature, concentration and stirring speed on the kinetics of copper cementation in order to establish the best conditions to obtain copper-rich cements. Thus synthetic solutions have been used to study the cementation of copper and cadmium in the presence of zinc powder, and the results of such studies are described below.

\section{MATERIALS AND METHODS}

\section{I Cementation Tests}

Cementation tests were carried out in a jacked reactor with a thermostatic bath Nova Ética, mod. 500/3D. The amount of zinc powder to be added to the reactor was previously determined by tests using the following stoichiometric ratios $(\mathrm{Zn} / \mathrm{Cu}$ and $\mathrm{Zn} / \mathrm{Cd}): 0.5 / 1.0 ; 1.0 / 1.0$; I.25/I.0; I.5/I.0. Both $\mathrm{Cu}$ and $\mathrm{Cd}$ were introduced as sulfates (analytical grade) and the $\mathrm{pH}$ of the solutions were adjusted to 4.0 . The concentrations used in this study were lower than $2.0 \mathrm{~g} . \mathrm{L}^{-1}$ and are typical of brazilian RLE process plants. In this preliminary study, the influence of the initial concentration of zinc was not considered and no background zinc was used in the solutions.

Reactions were carried out at $30,35,40,50$ and $60^{\circ} \mathrm{C}$ and an Arrhenius plot was used to determine the activation energy of the process. Different stirring speeds were also used in order to assess their influence on the cementation rates of both $\mathrm{Cu}$ and $\mathrm{Cd}$. For all reactions $500 \mathrm{~mL}$ solutions of the metals to be cemented were used and $3 \mathrm{~mL}$ samples were taken at pre-established intervals to monitor $\mathrm{Cu}^{2+}$ and $\mathrm{Cd}^{2+}$ solution concentrations.

\subsection{Chemical Analysis}

$\mathrm{Cu}^{2+}$ and $\mathrm{Cd}^{2+}$ concentrations were determined in a Varian 720-ES optical emission spectroscopy apparatus with inductively coupled plasma (ICP-OES).

\subsection{BET Analysis}

Surface areas of the resulting cements were measured in a Quantachrome mod. Nova-e BET analyzer.

\section{RESULTS AND DISCUSSION}

\section{I Copper Cementation}

Results for the cementation of copper in the presence of different amounts of zinc powder (Figure I) show that cementation rate increases and the final content of copper ions in solution decreases with increasing amount of zinc. In order to assure an acceptable yield for the process, all the subsequent experiments were carried out with a stoichiometric ratio 1.25:1.00, since at this ratio most of the copper in solution (98.3\%) could be extracted.

The effect of stirring speed was evaluated at $35^{\circ} \mathrm{C}$ (Figure 2) and it was observed that above $300 \mathrm{rpm}$ it no longer influences the cementation rate of copper. Therefore all the subsequent experiments were performed with a stirring speed of $300 \mathrm{rpm}$.

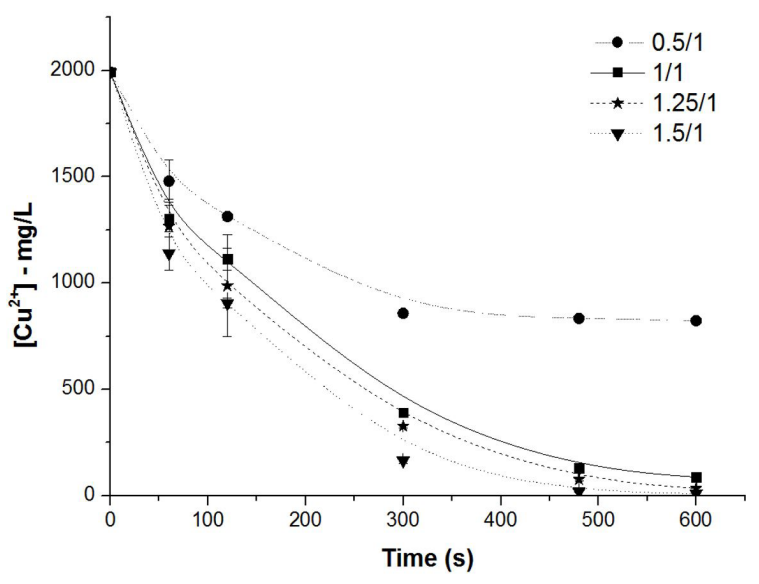

Figure I. Concentration of copper in solution as a function of time for different $\mathrm{Zn}: \mathrm{Cu}^{2+}$ ratios.

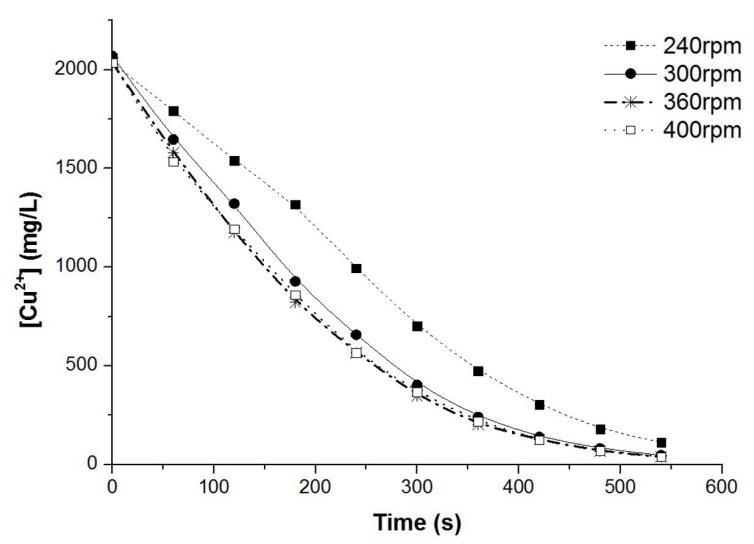

Figure 2. Effect of stirring speed on copper cementation. 
It is generally agreed that the rate controlling step in the cementation process is the diffusion of copper ions towards the zinc surface $[1,2,4-6,14-20]$. Kinetics of the cementation process is usually expressed by Equation 4, which describes the variation of the copper concentration with time.

$$
\frac{d C}{d t}=\frac{d m}{V d t}=-\frac{D A}{V \delta} C_{M e^{2+}}=-\frac{k A C_{M e^{2+}}}{V}
$$

In this equation $\mathrm{C}_{\mathrm{Me} 2+}$ is the concentration (mol/L) of metallic ions in solution at the time $t(\mathrm{~s}), m$ is the mass of the metallic species, $A$ is the area $\left(\mathrm{cm}^{2}\right)$ available for reaction to occur, $\delta$ is the thickness of the diffusion layer, $D$ is the diffusion coefficient $\left(\mathrm{cm}^{2} / \mathrm{s}\right), V$ is the solution volume and $k$ is the rate constant of cementation or the mass transfer coefficient, which depends on the fluid flow and temperature conditions $(\mathrm{cm} / \mathrm{s})$. One possible solution for such Equations 5 and 6 is which gives:

$$
\begin{aligned}
& \ln \frac{C_{M e^{2+}}}{C_{M e^{2+}}^{o}}=-\frac{k A}{V} t \\
& C_{M e^{2+}}=C_{M e^{2+}}^{o} \exp \left(\frac{-k A t}{V}\right)
\end{aligned}
$$

Plotting $\ln C_{C u} \times$ time for a given temperature should give a straight line and the mass transfer coefficient can be obtained from the slope. Figure 3 shows such plot for an experiment carried out at $40^{\circ} \mathrm{C}$ with a stirring rate of $300 \mathrm{rpm}$. Similar behavior was observed for the experiments carried out at $30,35,50$ and $60^{\circ} \mathrm{C}$. From the plots two stages could be associated with the processes: one initial stage when the reaction is slow followed by a rapid step. Table I lists the angular coefficient, the mass-transfer and the correlation coefficients obtained at each temperature from the plots for both stages identified in Figure 3 .

The surface area of the zinc particles used in this experiment was found to be $0.072 \mathrm{~m}^{2} / \mathrm{g}$ and this value was used to determine the mass transfer coefficient. The results indicate that, unlike other heterogeneous systems, in cementation processes products do not prevent the reaction progress but seem to promote an increase in its rate instead. This rate increase is assigned to the increase of the surface area available to the cementation, which in turn is related to morphological features of the resulting copper deposit $[1,14,16]$. Longer reaction times resulted in larger mass transfer coefficients and the reaction rate increased with higher temperatures. Based on these results, experiments were carried out with different initial copper concentrations in order to investigate its influence in the kinetic curves (Figure 4).

As the copper concentration increases, the second stage of the reaction starts earlier. Indeed some authors claim that for very high concentrations the first stage can even disappear [19]. At the low concentration of $0.05 \mathrm{~g} / \mathrm{L}$ the kinetic curve did not show a second stage either and a possible explanation for this result is that after cementation of all the copper present in solution, the surface area does not change considerably. Therefore, in dilute solutions, the increase in surface area promoted by the cemented copper is too small compared to the total area available for

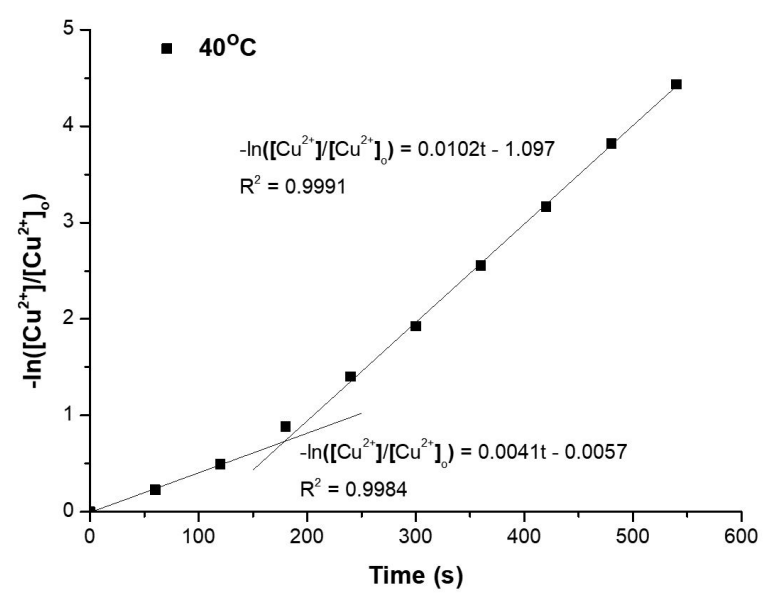

Figure 3. Plot of $-\log \left(\left[\mathrm{Cu}^{2+}\right] /\left[\mathrm{Cu}^{2+}\right]_{0}\right)$ versus time for the experiments carried out at $40^{\circ} \mathrm{C}$ and $300 \mathrm{rpm}$.

Table I. Kinetic data for both stages of the cementation of copper carried out at different temperatures

\begin{tabular}{cccc}
\hline Temp. $\left({ }^{\circ} \mathbf{C}\right)$ & $\boldsymbol{R}^{2}$ & $\begin{array}{c}\text { Angular } \\
\text { coefficient }\end{array}$ & $\begin{array}{c}\text { Mass transfer } \\
(\mathbf{c m} / \mathbf{s})\end{array}$ \\
\hline 30 & 0.9984 & 0.0041 & $2.85 \times 10^{-3}$ \\
& 0.9985 & 0.0077 & $5.35 \times 10^{-3}$ \\
35 & 0.9999 & 0.0037 & $2.57 \times 10^{-3}$ \\
& 0.9995 & 0.0089 & $6.18 \times 10^{-3}$ \\
40 & 0.9984 & 0.0041 & $2.85 \times 10^{-3}$ \\
& 0.9991 & 0.0102 & $7.08 \times 10^{-3}$ \\
50 & 0.9962 & 0.0051 & $3.54 \times 10^{-3}$ \\
& 0.9999 & 0.0113 & $7.85 \times 10^{-3}$ \\
60 & 0.9854 & 0.0070 & $4.86 \times 10^{-3}$ \\
& 0.9993 & 0.0129 & $8.96 \times 10^{-3}$ \\
\hline
\end{tabular}

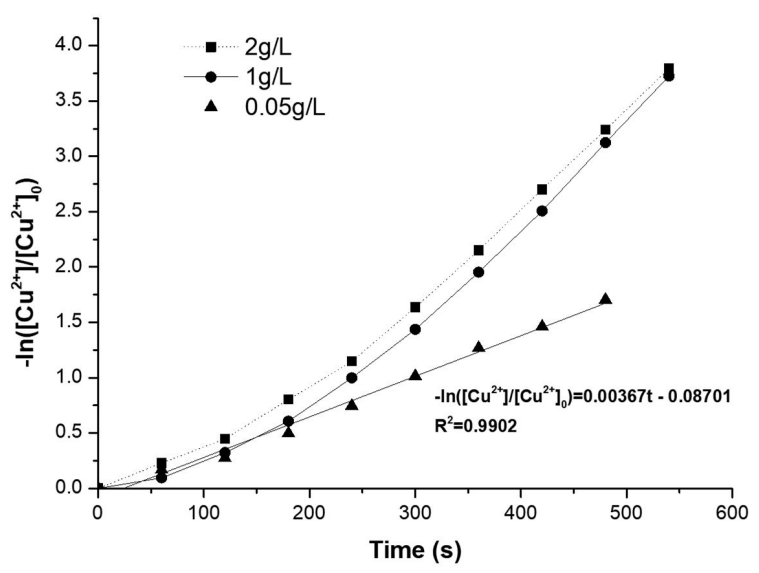

Figure 4. Plot of $-\log \left(\left[\mathrm{Cu}^{2+}\right] /\left[\mathrm{Cu}^{2+}\right]_{0}\right)$ against time for experiments carried out with different $\mathrm{Cu}^{2+}$ concentrations. 
cementation and, thus, no significant changes in the slopes are observed as it would for more concentrated solutions.

From the integrated form of Arrhenius equation (Figure 5) the activation energy for the initial step was found to be $21.5 \mathrm{~kJ} / \mathrm{mol}$ and for the second step, $13.8 \mathrm{~kJ} / \mathrm{mol}$. These values are similar to those reported by other authors $[1,17,19]$ and support our initial assumption that the controlling step takes place via transport.

In order to find the function describing the effect of surface area variation on the cementation kinetics, experiments were carried out at $30^{\circ} \mathrm{C}$ with $300 \mathrm{rpm}$ stirring speed and a 1.25:1.00 stoichiometric ratio of $\mathrm{Zn}: \mathrm{Cu}$. The reaction was interrupted at 60, 150, 450 and $600 \mathrm{~s}$ and the surface area of the resulting cement was measured each time (Figure 6). The surface area increased from $0.072 \mathrm{~m}^{2} / \mathrm{g}$ in the zinc powder up to $12.2 \mathrm{~m}^{2} / \mathrm{g}$ after $600 \mathrm{~s}$, which explains the change in slope of the kinetic curves.

Assuming the surface area $(A)$ change follows a power law, based on Figure 6, the data was submitted to a curve fitting process to give the following equation:

$$
A(t)=0.072+0.4804 t^{1 / 2}
$$

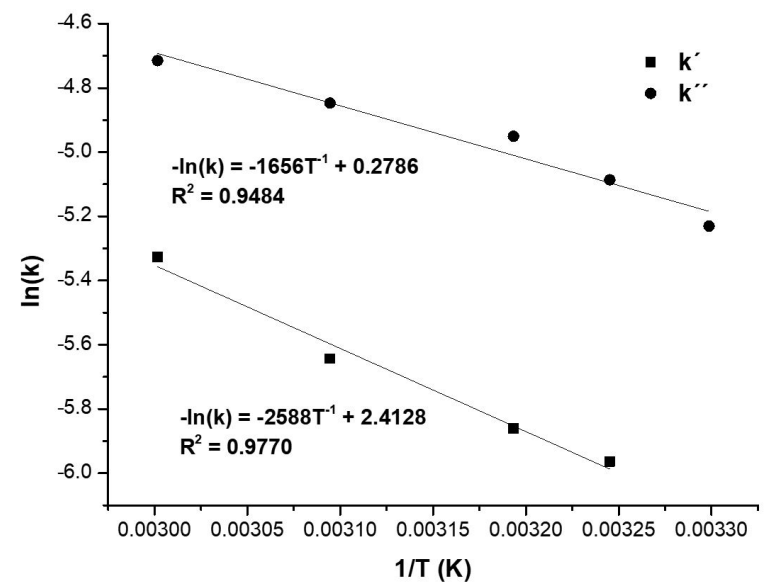

Figure 5. Arrhenius plot for the copper cementation ( $k^{\prime}=$ first stage; $k^{\prime \prime}=$ second stage).

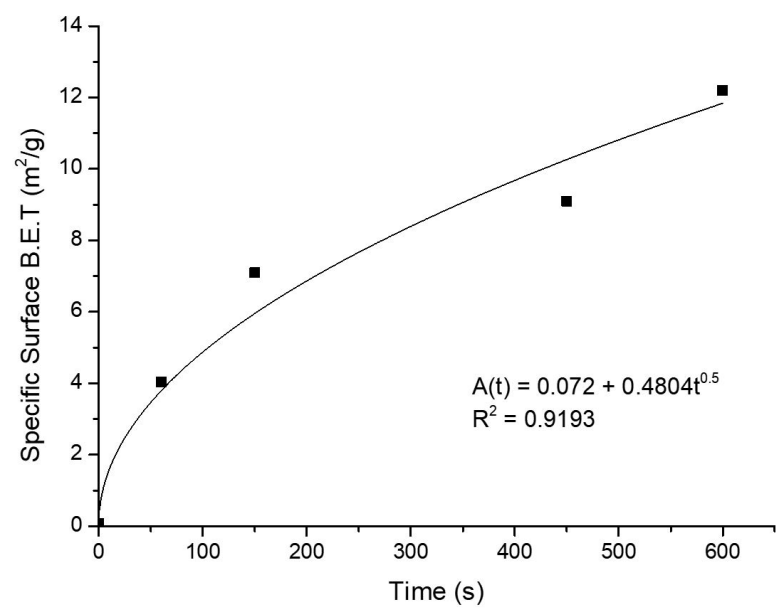

Figure 6. Change in surface area of the cement during reaction.
Given that the initial surface area of zinc powder $\left(0.072 \mathrm{~m}^{2} / \mathrm{g}\right)$ is too small compared to the cement, for longer intervals, the term related to the initial area in Equation 7 can be neglected and, therefore, the rate law for the cementing reaction can be expressed by Equation 8 :

$$
\begin{aligned}
& \frac{d C}{d t}=\frac{d m}{v d t}=-\frac{D A(t)}{v \delta} C_{M e^{2+}}=-\frac{0.4804 D t^{1 / 2} C_{M e^{2+}}}{v \delta} \\
& \ln \frac{C_{\mathrm{Me}^{2+}}}{C_{0_{M e^{2+}}}}=Q t^{3 / 2}
\end{aligned}
$$

According to Equation 9, plotting $-\ln \left(\mathrm{C} / \mathrm{C}_{0}\right)$ against $\mathrm{t}^{3 / 2}$ should give a straight line. Figure 7 shows a series of such plots obtained for different reaction temperatures. Values for the constant $Q$ and the corresponding correlation coefficients $\left(R^{2}\right)$ for each line are given in Table 2 .

From the Arrhenius plot (Figure 8) the activation energy was found to be $16.3 \mathrm{~kJ}$, which corresponds to an intermediate value when compared to those calculated from Figure 5, under the assumption of constant area. This value is also in accordance with a controlling step occurring via transport.

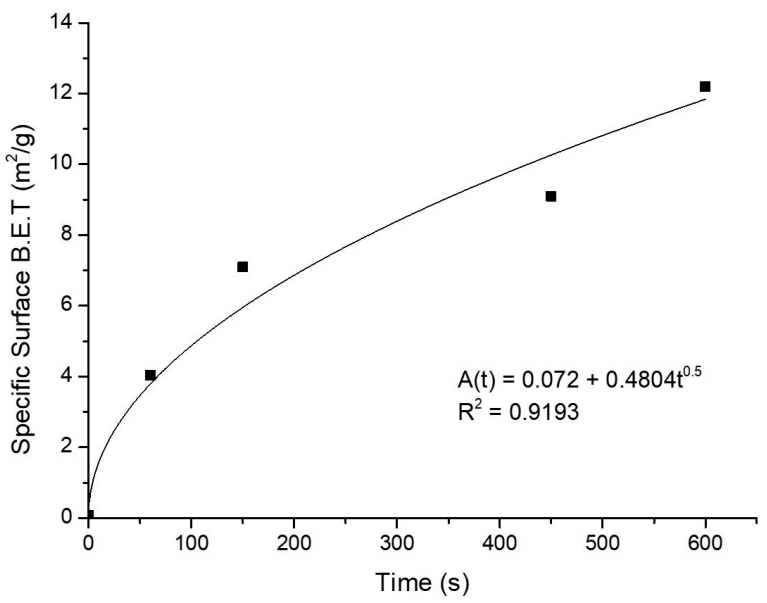

Figure 7. Plots of $-\ln \left(\left[\mathrm{Cu}^{2+}\right] /\left[\mathrm{Cu}^{2+}\right]_{0}\right)$ against $\mathrm{t}^{3 / 2}$ for different temperatures.

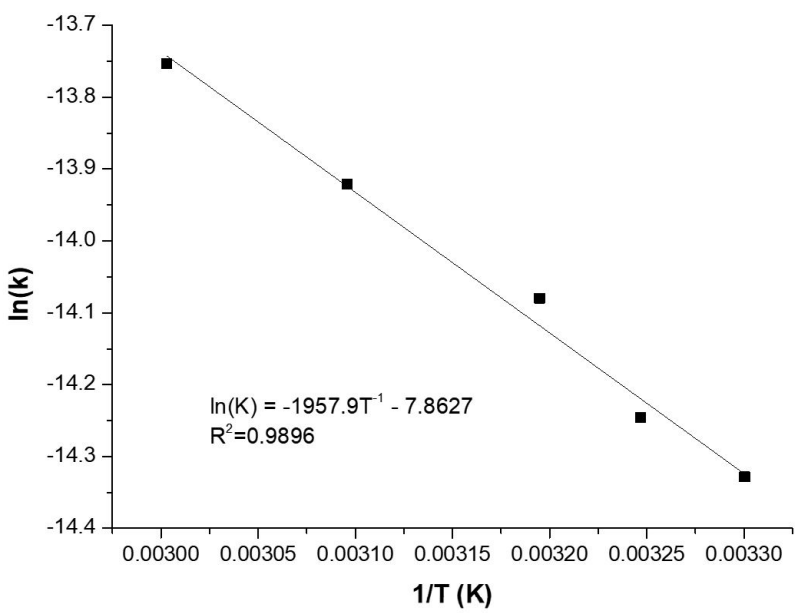

Figure 8. Arrhenius plot for the cementation of copper. 
Table 2. Values for the constant $Q$ and the correlation coefficient $R^{2}$ at different temperatures

\begin{tabular}{lccccc}
\hline & $\mathbf{3 0 ^ { \circ } \mathbf { C }}$ & $\mathbf{3 5 ^ { \circ } \mathbf { C }}$ & $\mathbf{4 0} 0^{\circ} \mathbf{C}$ & $\mathbf{5 0}^{\circ} \mathbf{C}$ & $\mathbf{6 0}^{\circ} \mathbf{C}$ \\
\hline $\mathbf{Q}$ & $5.975 \times 10^{-7}$ & $6.503 \times 10^{-7}$ & $7.677 \times 10^{-7}$ & $8.998 \times 10^{-7}$ & $1.064 \times 10^{-6}$ \\
$\boldsymbol{R}^{2}$ & 0.997 & 0.999 & 0.999 & 0.996 & 0.991 \\
\hline
\end{tabular}

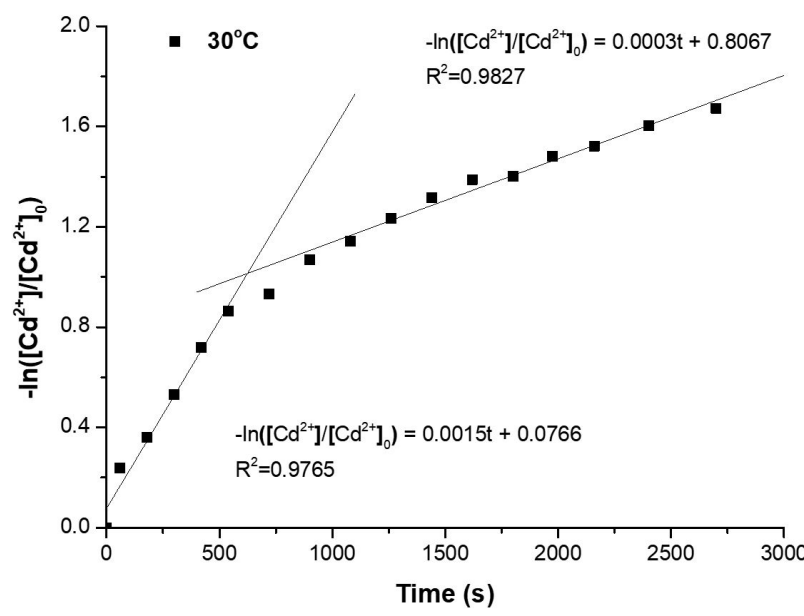

Figure 9. The plot of $-\log \left(\left[\mathrm{Cd}^{2+}\right] /\left[\mathrm{Cd}^{2+}\right]_{0}\right)$ versus time for the experiment carried out at $30^{\circ} \mathrm{C}$ and $300 \mathrm{rpm}$.

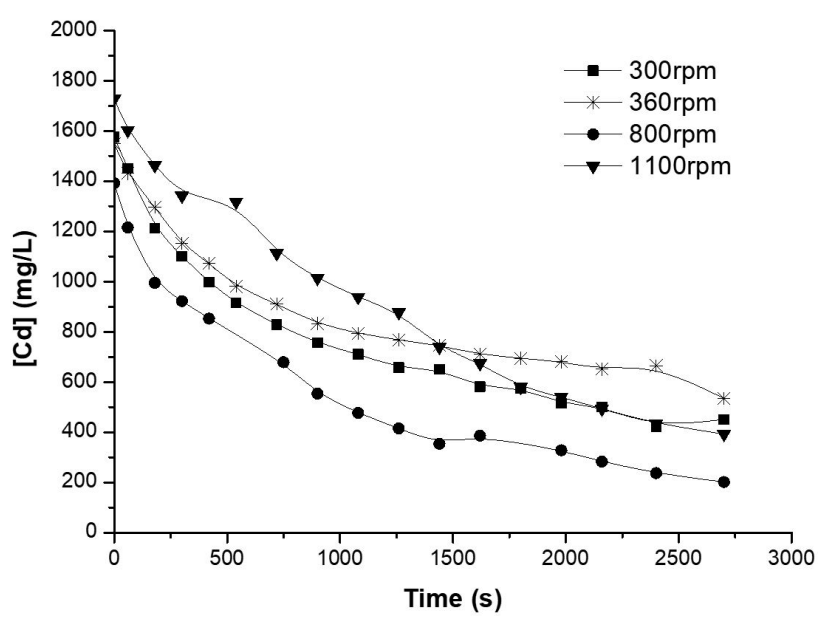

Figure 10. Cementation of cadmium under different stirring rates.

\subsection{Cadmium Cementation}

Rate constant values found in literature for the cementation of cadmium are rather controversial and some authors claim it decreases with time [7], while others show that it actually increases [ 14,21$]$. The results obtained for the cementation of cadmium at $30^{\circ} \mathrm{C}$ and $300 \mathrm{rpm}$ with a stoichiometric ratio Cd:Zn 1.25:1.00 (Figure 9) conform with the first case. The same behavior was observed at $35,40,50$ and $60^{\circ} \mathrm{C}$ and a rapid initial step followed by a slower step could be identified in the process. Table 3 lists the angular coefficient, the mass transfer coefficient and the correlation coefficient for all temperatures and both steps shown in Figure 9.

Unlike the cementation of copper, the results show that the rate constant for the cementation of cadmium decreases with time. Also the values found for the mass transfer coefficient were much smaller than those reported by other authors $[7,18,20]$. Both the rate constant and the mass transfer coefficient decreased at higher temperatures. A reduction in the cementation rate with temperature would in principle suggest a negative activation energy, but since this is impossible, it is more likely that some variable is masking the results. We suspected that the stirring rate could be having a negative influence because, in the case of cadmium, the stirring had to be increased to prevent the cement from agglomerating at the stirring speed of $300 \mathrm{rpm}$. Therefore the influence of stirring on the cementation rate was investigated and the results are shown in Figure 10.

The results show that the kinetics of cadmium cementation by zinc powder was randomly influenced by the increasing stirring rate. This behavior can be explained by noting that the cement $\mathrm{Zn} / \mathrm{Cd}$ resembles an alloy and cluster during the experiment. In this work, cluster formation could not be prevented even when the stirring rate was increased. While the copper cement is brittle, cadmium cement is plastic and can be molded as a clay.

Figure II shows the cadmium cement obtained with $1100 \mathrm{rpm}$ stirring rate. It can be seen that even at high stirring rates, the particle size increases during the

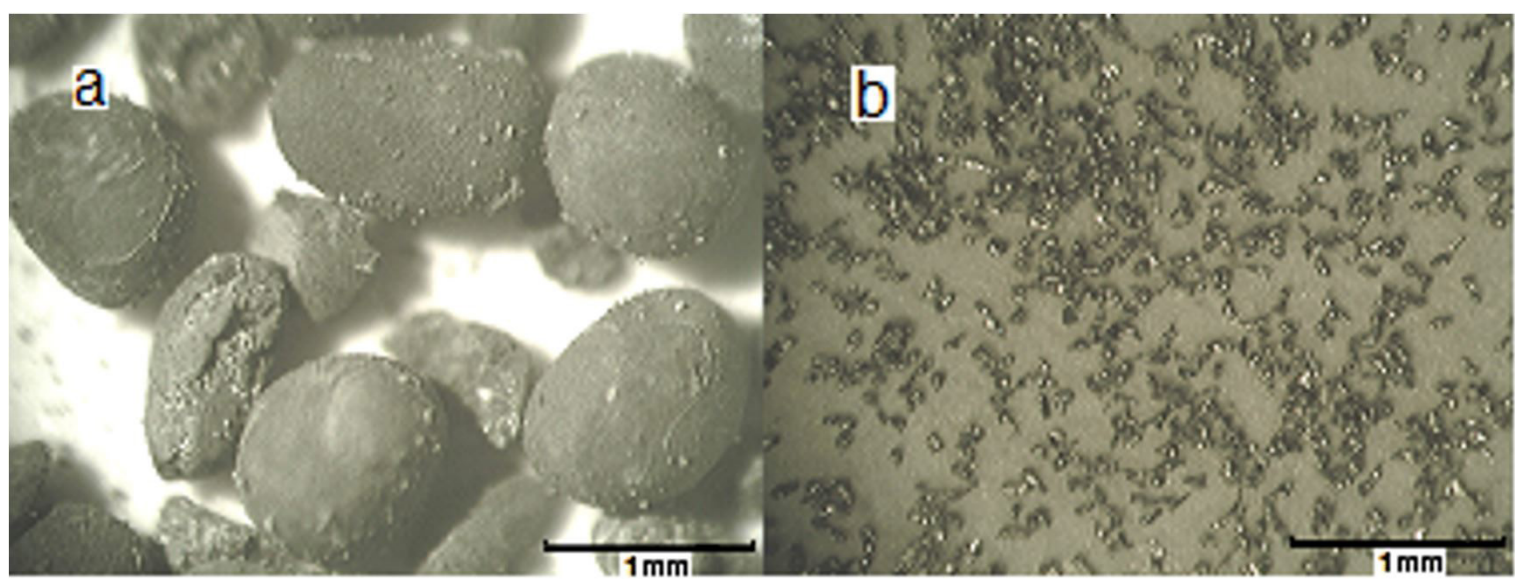

Figure II. (a) Cadmium cement obtained at I 100 rpm stirring rate and (b) zinc powder particles used in the experiment. 
Table 3. Kinetic data from the cementation of cadmium carried out at different temperatures

\begin{tabular}{ccrc}
\hline Temp. $\left({ }^{\circ} \mathbf{C}\right)$ & $\boldsymbol{R}^{\mathbf{2}}$ & $\begin{array}{r}\text { Angular } \\
\text { coefficient }\end{array}$ & $\begin{array}{c}\text { Mass transfer } \\
(\mathbf{c m} / \mathbf{s})\end{array}$ \\
\hline 30 & 0.9765 & $1.50 \times 10^{-3}$ & $1.04 \times 10^{-3}$ \\
& 0.9827 & $3.3 \times 10^{-4}$ & $2.29 \times 10^{-4}$ \\
35 & 0.9310 & $1.14 \times 10^{-3}$ & $7.92 \times 10^{-4}$ \\
& 0.9733 & $2.9 \times 10^{-4}$ & $2.01 \times 10^{-4}$ \\
40 & 0.9083 & $9.42 \times 10^{-4}$ & $6.54 \times 10^{-4}$ \\
& 0.9197 & $2.3 \times 10^{-4}$ & $1.60 \times 10^{-4}$ \\
50 & 0.8968 & $8.09 \times 10^{-4}$ & $5.62 \times 10^{-4}$ \\
& 0.9480 & $1.2 \times 10^{-4}$ & $8.33 \times 10^{-5}$ \\
60 & 0.7989 & $5.17 \times 10^{-4}$ & $3.59 \times 10^{-4}$ \\
& 0.9149 & $8.7 \times 10^{-5}$ & $6.04 \times 10^{-5}$ \\
\hline
\end{tabular}

experiment; this agglomeration decreases the surface area available to the reaction. Also bigger particles are produced at higher temperatures, which could explain the decrease on the reaction rate. Although the experiments have been carried out at higher stirring rates, agglomeration of the cement appears to be an intrinsic feature of the $\mathrm{Cd}-\mathrm{Zn}$ system and not a consequence of the reaction conditions. Some experiments are under way to try and characterize this material.

Some authors $[14,20]$ have reported that the cementation rate constant increases during the cementation of cadmium by zinc powder. In these experiments, the reaction was carried out using a rotating disc electrode, which prevents cement from agglomeration. With that in mind, we expected that a plot of $\ln \left(\left[\mathrm{Cd}^{2+}\right] /\left[\mathrm{Cd}^{2+}\right]_{0}\right)$ as a function of $\mathrm{t}^{3 / 2}$ would give a straight line, just like it was found to $\mathrm{Cu}^{2+}$.

Figure 12 shows some plots of $\ln \left(\left[\mathrm{Cd}^{2+}\right] /\left[\mathrm{Cd}^{2+}\right]_{0}\right)$ as a function of time for initial cadmium concentrations of $2, \mathrm{I}$ and $0,5 \mathrm{~g} / \mathrm{L}$. The results indicate that the reduction of $\left[\mathrm{Cd}^{2+}\right]$ in solution delays the second stage of the reaction. In fact, if the concentration of cadmium in solution is decreasing, cement agglomeration cannot take place, so the second stage of the reaction does not appear. On the other hand, at higher $\left[\mathrm{Cd}^{2+}\right]$, the second stage of the reaction starts earlier [7], as it was observed with copper. These results agree with those reported by some authors $[18,20]$ who showed a linear relation in the plot of $\ln \left(\left[\mathrm{Cd}^{2+}\right] /\left[\mathrm{Cd}^{2+}\right]_{0}\right)$ as a function of time, when working with cadmium concentrations lower than $500 \mathrm{ppm}$.

\subsection{Cementation of Copper and Cadmium}

After establishing the influence of process variables in the cadmium and copper cementation, a couple of experiments were conducted with a synthetic solution containing $\approx 2 \mathrm{~g} / \mathrm{L}$ of $\mathrm{Cd}$ and $\mathrm{Cu}$. The first experiment was carried out at conditions favoring the copper cementation: $300 \mathrm{rpm}, 10 \mathrm{~min}, 60^{\circ} \mathrm{C}$ and a stoichiometric ratio $\mathrm{Zn}: \mathrm{Cu}$ of 1.25: I (Figure 13); the second experiment was carried out at conditions favoring the cadmium cementation: $800 \mathrm{rpm}, 45 \mathrm{~min}$, $30^{\circ} \mathrm{C}$ and stoichiometric ratio $\mathrm{Zn}: \mathrm{Cd}$ of I.25: I (Figure 14).

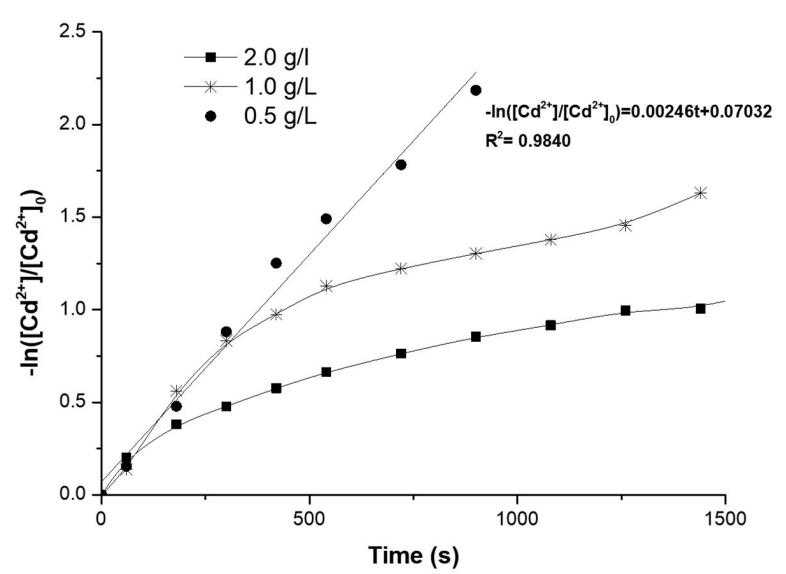

Figure 12. Cementation experiments carried out with different initial cadmium concentrations.

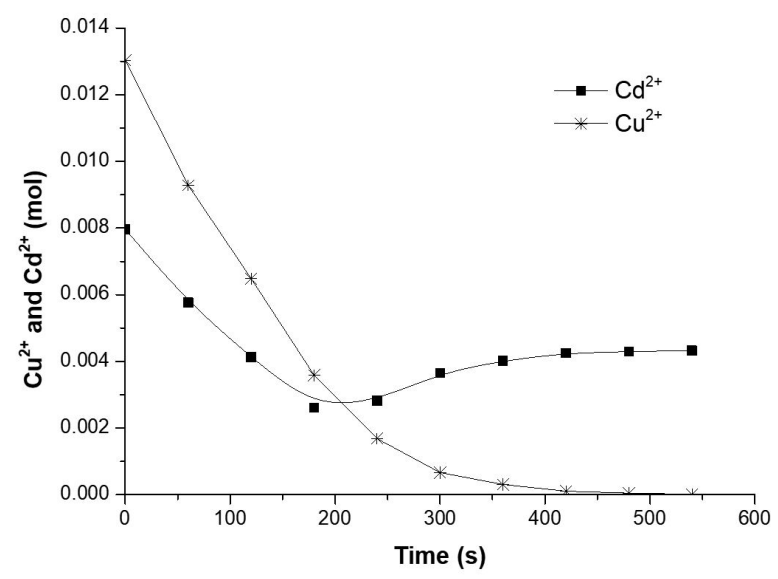

Figure 13. Cementation of $\mathrm{Cu}^{2+}$ and $\mathrm{Cd}^{2+}$ under conditions favoring the copper cementation.

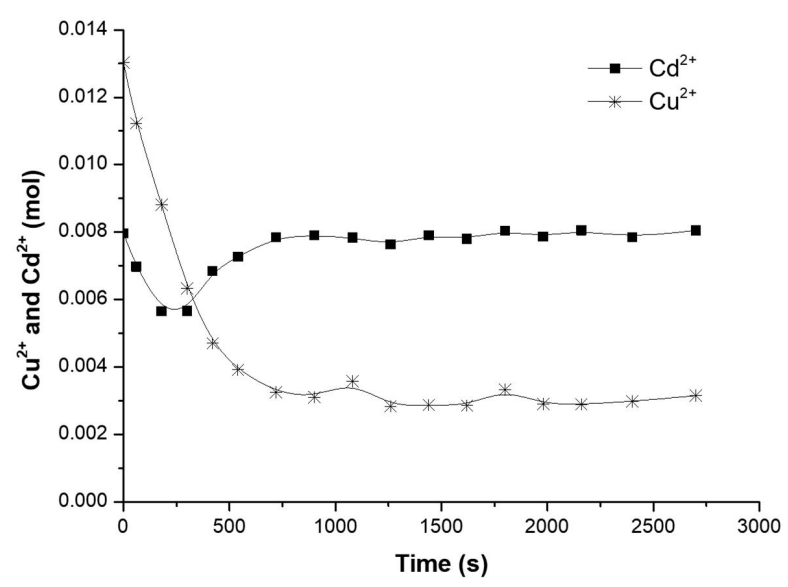

Figure 14. Cementation of $\mathrm{Cu}^{2+}$ and $\mathrm{Cd}^{2+}$ in conditions that support the cadmium cementation.

The results show that under conditions that favor copper cementation all of the copper was recovered while in the second case the solution still contained some $4 \mathrm{mmol}$ of copper. Despite the residual copper in this case, the cement was free of cadmium and its concentration was the 
same both at the beginning and the end of the experiment. The results also show that longer residence times entail a purer cement and the cadmium cementation benefits from the excess of zinc powder. Indeed, when the purpose was to cement cadmium, the amount of zinc powder was not enough to cement both metals, therefore, copper ends up being cemented by the cadmium-containing cement, according to Equation 10. In order that such reaction can occur, the amount of zinc powder must be limiting, therefore, after both $\mathrm{Cu}$ and $\mathrm{Cd}$ are cemented, the presence of copper in the solution and cadmium in the cement bring about the reaction represented by Equation $\mathrm{I} 0$ and $\mathrm{Cd}^{2+}$ ions return to the solution. When excess zinc powder was used, all of the copper was cemented and the reaction represented by Equation 10 did not take place; instead, the excess of zinc powder cemented the cadmium present in solution. Also the amount of zinc powder plays an important role when the purity of the cement is an issue. Copper cement was contaminated with in all experiments carried out with excess of zinc powder

$$
\mathrm{Cd}^{0}+\mathrm{Cu}^{2+} \rightarrow \mathrm{Cd}^{2+}+\mathrm{Cu}^{0} \quad \Delta G_{60^{\circ} \mathrm{C}}^{0}=-143 \mathrm{~kJ}
$$

\section{CONCLUSIONS}

A kinetic study of the cementation of copper and cadmium by zinc powder was conducted. The results showed that the diffusion of copper and cadmium ions to the zinc powder surface is the rate-controlling step. Agglomeration of the $\mathrm{Cd} / \mathrm{Zn}$ cement could not be avoided, even at high stirring rates and this had a strong influence on the results. At low copper and cadmium concentrations the area available to the cementation reaction could be considered constant and the plot of $-\ln \left(\left[\mathrm{Me}^{2+}\right] /\left[\mathrm{Me}^{2+}\right]_{0}\right)$ against time gave a straight line. On the other hand, at higher concentrations two steps were identified on those plots, and this was assigned to a variation of the surface area available to cementation. For the cementation of copper, this change in surface area with time could be expressed by the power law $A(t)=0.072+0.4804 t^{1 / 2}$. Thus, assuming a first order kinetics for the process with the surface area changing according to this law, a plot of $-\ln \left(\left[\mathrm{Me}^{2+}\right] /\left[\mathrm{Me}^{2+}\right]_{0}\right)$ against $\mathrm{t}^{3 / 2}$ gave a straight line. Purer copper cement was obtained when the experiments were carried out in the presence of less than stoichiometric amount of zinc powder and longer reaction times; this was reasoned as copper being cemented by cadmium.

\section{Acknowledgements}

The authors are grateful to Votorantim Metais - Juiz de Fora, for donating zinc powder and copper sulfate. GES] thanks Fundação Gorceix for funding through a PROMET grant.

\section{REFERENCES}

I Ahmed IM, El-Nadi YA, Daoud JA. Cementation of copper from spent copper-pickle sulfate solution by zinc ash. Hydrometallurgy. 201 I; I 10:62-66.

2 Dib A, Makhloufi L. Mass transfer correlation of removal of nickel by cementation onto rotating zinc disc in industrial zinc sulfate solutions. Minerals Engineering. 2007;20: I46-I5I.

3 Konsowa $\mathrm{AH}$. Intensification of the rate of heavy metal removal from wastewater by cementation in a jet reactor. Desalination. 2010;254:29-34.

4 Power GP, Ritchie IM. A contribution to the theory of cementation (metal displacement) reactions. Australian Journal of Chemistry. 1976;29:699-709.

5 Power GP, Ritchie IM. Metal displacement (cementation) reactions: The mercury(II)/copper system. Electrochimica Acta. 1977;22:365-37I.

6 Sędzimir JA. Precipitation of metals by metals (cementation) - kinetics, equilibria. Hydrometallurgy. 2002;64: I6I167.

7 Younesi SR, Alimadadi H, Alamdari EK, Marashi SPH. Kinetic mechanisms of cementation of cadmium ions by zinc powder from sulphate solutions. Hydrometallurgy. 2006;84:155- 164.

8 Farahmand F, Moradkhani D, Sadegh Safarzadeh M, Rashchi F. Optimization and kinetics of the cementation of lead with aluminum powder. Hydrometallurgy. 2009;98:8I-85.

9 Karavasteva $M$. The effect of certain surfactants on the cementation of nickel from zinc sulphate solutions by suspended zinc particles in the presence of copper. Canadian Metallurgical Quarterly. 1999;38:207-210.

I0 Gouvea LR, Morais CA. Recovery of zinc and cadmium from industrial waste by leaching/cementation. Minerals Engineering. 2007;20:956-958.

I I Safarzadeh MS, Bafghi MS, Moradkhani D, Ilkhchi MO. A review on hydrometallurgical extraction and recovery of cadmium from various resources. Minerals Engineering. 2007;46: I 332-I 340. 
Oliveira et al.

I 2 Safarzadeh MS, Moradkhani D, Ilkhchi MO. Determination of the optimum conditions for the cementation of cadmium with zinc powder in sulfate medium. Chemical Engineering and Processing: Process Intensification. 2007;20:21।-220.

I 3 Stanojević D, Nikolić B, Todorović M. Evaluation of cobalt from cobaltic waste products from the production of electrolytic zinc and cadmium. Hydrometallurgy. 2000;54:I5I-I60.

I4 Alemany C, Aurousseau M, Lapicque F, Ozil P. Cementation and corrosion at a RDE: changes in flow and transfer phenomena induced by surface roughness. Journal of Applied Electrochemistry. 2002;32:I269-I278.

I5 Amin NK, El-Ashtoukhy ESZ, Abdelwahab O. Rate of cadmium ions removal from dilute solutions by cementation on zinc using a rotating fixed bed reactor. Hydrometallurgy. 2007;89:224-232.

I6 Dib A, Makhloufi L. Mass transfer correlation of simultaneous removal by cementation of nickel and cobalt from sulphate industrial solution containing copper: Part II: onto zinc powder. Chemical Engineering Journal. 2006; 123:53-58.

17 Gros F, Baup S, Aurousseau M. Copper cementation on zinc and iron mixtures: Part I: results on rotating disc electrode. Hydrometallurgy. 201 I;106:127-133.

I 8 Karavasteva $M$. The effect of certain surfactants on the cementation of cadmium by suspended zinc particles. Hydrometallurgy. 1997;47:91-98.

19 Wadsworth ME, Miller JD. Hydrometallurgical processes. In: Sohn HY, Wadsworth ME. editors. Rate processes of extractive metallurgy. New York: Plenum Press; 1979. p. 133-244.

20 Taha AA, Abd El-Ghani SAH. Effect of surfactants on the cementation of cadmium. Journal of Colloid and Interface Science. 2004;280:9-17.

2I Lee EC, Lawson F, Han KN. Effect of precipitant surface roughness on cementation kinetics. Hydrometallurgy. | 978;3:7-21.

Received: 19 Feb. 2018

Accepted: 15 Jan. 2019 